\title{
Effect of bottom stress formulation on modelled flow and turbidity maxima in cross-sections of tide-dominated estuaries
}

\author{
George P. Schramkowski • Huib E. de Swart • \\ Henk M. Schuttelaars
}

Received: 30 November 2008 / Accepted: 15 September 2009 / Published online: 29 October 2009

(C) Springer-Verlag 2009

\begin{abstract}
A three-dimensional numerical model with a prognostic salinity field is used to investigate the effect of a partial slip bottom boundary condition on lateral flow and sediment distribution in a transect of a tidally dominated channel. The transect has a symmetrical Gaussian cross-channel bottom profile. For a deep, well-mixed, tidally dominated channel, partial slip decreases the relative importance of Coriolis deflection on the generation of cross-channel flow patterns. This has profound implications for the lateral distribution of residual salinity that drives the cross-channel residual circulation pattern. Transverse sediment transport, however, is always found to be governed by a balance between advection of residual sediment concentration by residual lateral flow on the one hand and cross-channel diffusion on the other hand. Hence, the changes in the cross-channel distribution of residual salinity modify the lateral sediment distribution. For no slip, a single turbidity maximum occurs. In contrast,
\end{abstract}

Responsible Editor: Alejandro Jose Souza

\author{
G. P. Schramkowski $(\varangle)$ \\ Flanders Hydraulic Research, \\ Berchemlei 115, 2140, Antwerp, Belgium \\ e-mail: George.Schramkowski@mow.vlaanderen.be \\ H. E. de Swart \\ Institute for Marine and Atmospheric research Utrecht, \\ University of Utrecht, PO Box 80000, \\ Utrecht, The Netherlands \\ e-mail: h.e.deswart@uu.nl \\ H. M. Schuttelaars \\ Delft Institute of Applied Mathematics, \\ Delft University of Technology, \\ Mekelweg 4, 2624 CD, Delft, The Netherlands \\ e-mail: h.m.schuttelaars@tudelft.nl
}

partial slip gives a gradual transition to a symmetrical density distribution with a turbidity maximum near each bank. For a more shallow, partially mixed tidal channel that represents the James River, a single turbidity maximum at the left bank is found irrespective of the near-bed slip condition. In this case, semi-diurnal contributions to sediment distribution and lateral flow play an important role in cross-channel sediment transport. As vertical viscosity and diff usivity are increased, a second maximum at the right bank again exists for partial slip.

Keywords Turbidity $\cdot$ Estuary $\cdot$ Sediment transport • Morphodynamic equilibrium

\section{Introduction}

An important factor for the functioning of estuaries is the distribution of suspended matter in those systems. High suspended sediment concentrations (hereafter called SSC) cause, for example, strong extinction of light, thereby hampering the growth of algae. Also, turbid waters usually have low oxygen concentrations because organic material in the sediment consumes oxygen. This can lead to hypoxic zones (cf Uncles et al. 1998; Garnier et al. 2001; Talke et al. 2009).

Field data collected in partially mixed and wellmixed estuaries reveal the presence of pronounced local maxima in SSC, when moving in both the longitudinal direction (Kappenberg and Grabemann 2001; Blake et al. 2001; Lin and Kuo 2001; North et al. 2004; Uncles et al. 2006) and the lateral direction (Nichols 1972; Geyer et al. 1998; Fugate et al. 2007). Various models have been developed to explain the entrapment 
of sediments in specific areas. These models are based on the concept that SSC is the result of erosion and transport of material by the flow, the latter being forced by tides, density differences, fresh water discharge and wind. Many studies focus on the along-estuary distribution of SSC. They stress the importance of gravitational circulation and river discharge (Festa and Hansen 1978), asymmetry in turbulent mixing during the tidal cycle (Jay and Musiak 1994; Prandle 2004) and wind (North et al. 2004).

Fewer studies have been devoted to the lateral entrapment of sediments. Geyer et al. (1998) demonstrated that an important mechanism of trapping is that the baroclinic pressure gradient force and Coriolis force act together during one phase of the tide, whereas they oppose each other during the other phase of the tide. Huijts et al. (2006) developed an idealised, analytical model in which the flow and sediment distribution are explicitly computed in a cross-section of a tide-dominated estuary. Their solution is obtained by imposing that the total, net lateral sediment transport vanishes at each location. The final result is a balance between advective transport and diff usive transport.

As is shown by Huijts et al. (2006), their model is able to simulate the zone of lateral entrapment in an estuarine section of the James River estuary. Moreover, the model is fast and allows for systematic analysis in terms of physical mechanisms. A drawback is that several rather strong assumptions are employed, which are not always met in the field. In particular, the tidal velocity amplitude must be large compared to that of the residual flow (forced by, e.g. density gradients and tidal rectification), the density field is diagnostic and conditions in the along-estuary direction must be approximately uniform. These considerations motivated Schramkowski et al. (2008) to design a model, which is prognostic in the density and valid for a wider range of parameter settings. Such a model is, unavoidably, more complex and must be solved numerically. Interpretation of the stand-alone results of a complex model is difficult, but it is demonstrated in the paper that, when the idealised model is used as an additional diagnostic tool, considerable insight in the dynamics is obtained, even outside the parameter regime for which the idealised model is valid. This model provides a link between simple analytical models and full-scale, stateof-the-art numerical models (cf. Burchard et al. (2004)).

The objective of the present paper is, using numerical modelling, to explore the sensitivity of turbidity maxima in an estuarine cross-section to formulation for the bottom boundary condition. In this respect, a major assumption of the analytical model of Huijts et al. (2006) is that the vertical eddy viscosity $A_{v}$ and eddy diff usion coefficient $K_{v}$ are constants and a no-slip condition for the flow is imposed at the bed. However, it is known that, near the bed, $A_{v}$ and $K_{v}$ become very small and that the flow has a logarithmic profile in the near-bed layer. Here, we adopt the simplest way to account for the presence of this logarithmic layer, i.e. a partial slip model (see, e.g. Csanady (1982); Maas and van Haren (1987)). This means that the domain in which the flow is computed consists of a layer in which $A_{v}, K_{v}$ are constant, but this layer has its lower boundary at about $1 \mathrm{~m}$ from the bed. Underneath this lower boundary, the flow behaves logarithmically. At the transition between the two layers, the shear stress is imposed as a given, nonlinear function of the local velocity at this level. The ratio of stress and (finite) velocity at this level is a measure of the degree of slip in the model.

The numerical model is introduced in Section 2. Results are presented in Section 3, followed by a discussion in Section 4 and conclusions in Section 5.

\section{Model setup}

We adopt TRIWAQ (Stelling 1984), which is a numerical model that solves the three-dimensional, shallowwater equations with prognostic salt dynamics. The model uses an orthogonal grid in the horizontal direction, while the vertical is discretised by means of sigma layers. Below, the model specifications will be discussed in more detail.

\subsection{Geometry and forcing conditions}

The domain used in this study consists of a straight tidal channel of length $L$ and uniform width $B$ (see Fig. 1). The model is forced at the seaward side by a prescribed vertical $M_{2}$ tide (water level). This water level variation drives the dominant tidal water motion

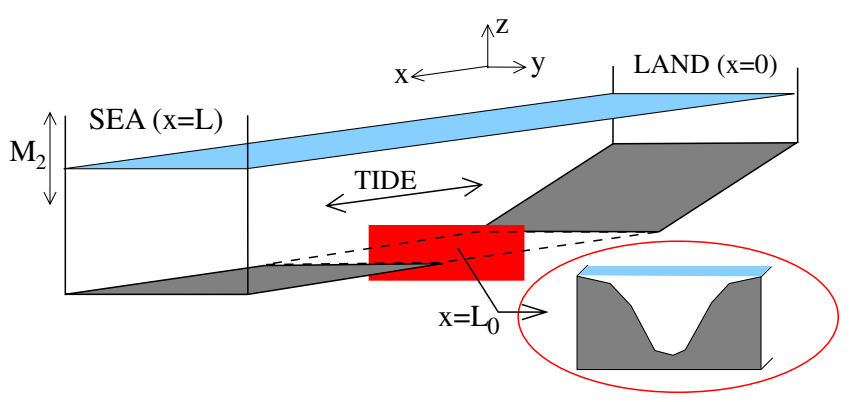

Fig. 1 Schematic representation of the numerical model domain. The Gaussian transect at $x=L_{0}$ is shown enlarged. For further details, see main text 
inside the basin. At the landward opening, a zero discharge condition is imposed. This condition requires that the channel length $L$ is chosen sufficiently long so that the tidal wave that enters at $x=L$ has decayed near the landward side. At the landward and seaward boundaries, we prescribe constant salinity values $S_{\text {land }}$ and $S_{\text {sea }}>S_{\text {land }}$, respectively. These forcings drive the baroclinic part of the water motion, which is typically an order of magnitude weaker than the tidal flow.

A Cartesian coordinate system $\{x, y, z\}$ is adopted, with $x, y$ and $z$ pointing in the along-channel, crosschannel and vertical directions, respectively. In the landward region $\left(x<L_{1}\right)$, the bottom is linearly sloping and decreases up-estuary from $H_{1}$ to $H_{2}<H_{1}$ to increase damping of the tidal wave. In the region near the seaside $\left(x>L_{2}\right)$, the bed is horizontal. In the intermediate zone $\left(L_{1}<x<L_{2}\right)$, the bathymetry changes gradually. In this paper, we focus on the flow and sediment dynamics at the central part of this zone $\left(x=L_{0}=\left(L_{1}+L_{2}\right) / 2\right)$. Inside this transect, the lateral depth variation is Gaussian and is given by

$$
H(y)=H_{\max } \mathrm{e}^{-\left(\frac{y-B / 2}{b}\right)^{2}},
$$

where $H_{\max }$ is the maximum depth in the transect and $b / B$ a measure for the steepness of the lateral bed variation.

The motivation to select this geometry is to create a situation in which, near $x=L_{0}$, the flow is approximately along-channel uniform. This allows us to study the lateral distribution of flow and sediment concentration in isolation. To obtain a locally along-channel uniform flow, the along-channel pressure gradient near $x=L_{0}$ has to be nearly constant. This is established by choosing a high coefficient for horizontal diff usion, $K_{h}$, in the regions near the landward and seaward boundaries $\left(x \leq L_{1}\right.$ and $\left.x \geq L_{2}\right)$ so that the salinity values in these regions are effectively equal to the boundary values. In the intermediate zone $\left(L_{1}<x<L_{2}\right)$, a standard value for this diffusion is used. As a consequence, the along-channel salinity gradient is spatially constrained to the intermediate zone. For given boundary values of salinity, this gives a reasonably fixed value for the longitudinal residual density gradient so that the along-channel baroclinic forcing is approximately constant.

\subsection{Partial slip parameterisation}

As is already argued in Section 1, the partial slip formulation is adopted here. Thus, the vertical viscosity coefficient $A_{\mathrm{v}}$ is taken constant. Within the numerical model, bottom stress $\tau$ is calculated by using the standard quadratic friction law

$\boldsymbol{\tau}=\rho \frac{g}{C^{2}}\left\|\mathbf{u}_{\mathrm{h}}\right\| \mathbf{u}_{\mathrm{h}}$,

where $C$ denotes the Chezy parameter. The vector $\mathbf{u}_{\mathrm{h}}$ is the horizontal velocity vector at the bed; its components $u$ and $v$ are in the $x$ and $y$ directions, respectively. For a partial slip formulation, bottom friction is related to vertical eddy viscosity $A_{\mathrm{v}}$ and near bed velocity by the identification

$\boldsymbol{\tau}=\rho A_{\mathrm{v}} \frac{\partial \mathbf{u}_{\mathrm{h}}}{\partial z}=\rho s \mathbf{u}_{\mathrm{h}}$.

The first identity is true by definition, the second equality defines the partial slip parameterisation for turbulent flow. The quantity $s$ is the stress or slip parameter. Strictly speaking, Eq. 2 is to be evaluated at the top of the logarithmic layer (approximately $1 \mathrm{~m}$ above the bed) rather than at the true bed.

In general, $s$ depends on time and the lateral position $y$. However, we can linearise the bed shear stress such that the slip parameter can be represented by a single, representative constant value. The latter value is obtained by requiring that the time and width averaged energy dissipation by bottom friction is the same for both the nonlinear friction law and the partial slip formulation. This gives

$s=\frac{\overline{<\boldsymbol{\tau} \cdot \mathbf{u}_{\mathrm{h}}>}}{\overline{\left.<\rho\left\|\mathbf{u}_{\mathrm{h}}\right\|^{2}\right\rangle}}$,

where (for any quantity $Q$ ) $<Q>$ and $\bar{Q}$ denote tidal and width averaging, respectively. In the remainder of this paper, $s$ is understood to be equal to the constant value defined by Eq. 3.

Physically, $s$ measures the degree of velocity slip near the bed. The nondimensional parameter controlling the degree of slip is $s \bar{H} / A_{\mathrm{v}}$, where $\bar{H}$ is the width averaged bottom depth. If $s \bar{H} / A_{\mathrm{v}} \gg 1$, the near-bed velocity vanishes (no slip boundary) while $s \bar{H} / A_{\mathrm{v}} \ll 1$ corresponds to a stress-free boundary. The numerical model can give tidal flow corresponding to a wide range of slip parameter values by changing the bottom roughness, which determines the Chezy coefficient.

\subsection{Sediment module}

The water motion that is computed by the numerical model is used by a $2 D V$ sediment transport module to compute the cross-channel distribution of sediment. This module is similar to the one adopted by Huijts et al. (2006), and will now be outlined. 
The local vertical distribution of sediment is determined by the balance between upward diffusion and downward settling, which reads

$\frac{\partial c}{\partial t}-w_{\mathrm{s}} \frac{\partial c}{\partial z}=\frac{\partial}{\partial z}\left(K_{\mathrm{v}} \frac{\partial c}{\partial z}\right)$,

where $c$ is the sediment concentration and $w_{\mathrm{s}}$ denotes the sediment settling velocity. The parameter $K_{\mathrm{v}}$ is the coefficient of vertical diffusion. It is assumed that $K_{\mathrm{v}}$ is constant and that its value is equal to that of $A_{\mathrm{v}}$. The boundary conditions to Eq. 4 are that there should be no sediment flux through the water surface and that the sediment flux at the bed equals the erosive flux, i.e.

$K_{\mathrm{v}} \frac{\partial c}{\partial z}+w_{\mathrm{s}} c=0$ at $z=0 \quad$ and

$K_{\mathrm{v}} \frac{\partial c}{\partial z}=-E$ at $z=-H(y)$,

respectively. The erosion flux $E$ is given by $E=w_{\mathrm{s}} c_{\star}$, where $c_{\star}$ is the reference concentration. The reference concentration is determined by the local bed shear stress and the availability of sediment and reads

$c_{\star}=\rho_{\mathrm{s}} \frac{\|\boldsymbol{\tau}\|}{\rho g^{\prime} d_{\mathrm{s}}} a(y)$,

where $\rho_{\mathrm{S}}$ denotes density of sediment, $g^{\prime}=g\left(\rho_{\mathrm{S}}-\rho\right) / \rho$ is reduced gravity and $d_{\mathrm{s}}$ denotes sediment grain size. Furthermore, $a(y)$ denotes the sediment availability function. Physically, $a(y)$ is a measure of the amount of sediment in the bed that is available for erosion.

Note that advection and horizontal diff usion of sediment are neglected in Eq. 4, because their magnitude is much smaller than those of the retaining terms. Nevertheless, these terms yet play a role in the model, as argued below. The solution of Eqs. 4 and 5 still leaves the lateral dependence of sediment availability undetermined. This availability is obtained by imposing a morphodynamic equilibrium condition (Friedrichs et al. 1998), which states that there is no net lateral sediment transport $F$, i.e.

$F=\left\langle\int_{-H(y)}^{0}\left[v c-K_{\mathrm{h}} \frac{\partial c}{\partial y}\right] d z\right\rangle=0$,

where $v$ is the across-channel velocity component. This constraint gives $a(y)$ up to a multiplicative constant, which is determined by additionally specifying the cross-channel averaged value $a_{\star}$ of $a(y)$. The value of $\rho_{\mathrm{s}} a_{\star}$ measures the total amount of sediment that is available for erosion. It is an empirical quantity that can be used a posteriori as a tuning parameter. Since this paper focusses on the qualitative behaviour of crosschannel sediment distribution (i.e. location of turbidity maximum), the numerical value of $a_{\star}$ is not relevant.

\subsection{Postprocessing of model results}

The numerical model results at the Gaussian transect are processed as follows. First, the full flow data are used to obtain the horizontal velocity vector and its vertical gradient at the bed. From this, the linearised stress parameter $s$ is determined by adopting Eq. 3 . Next, the flow and salinity field are decomposed into the residual part and the non-residual harmonic components $M_{2}, M_{4}$ and $M_{6}$. Hence, any quantity $Q$ can be approximated by the harmonic truncated series

$Q=<Q>+Q_{\mathrm{M} 2}+Q_{\mathrm{M} 4}+Q_{\mathrm{M} 6}$,

where subindices denote the corresponding tidal component. Similarly, the net lateral sediment transport $F$ can be written as

$F=F_{\mathrm{M} 0}+F_{\mathrm{M} 2}+F_{\mathrm{M} 4}+F_{\mathrm{M} 6}+F_{\text {diff }}$,

where subindices $M_{0}-M_{6}$ refer to contribution of tidal constituents to the advective sediment transport, i.e.

$F_{\mathrm{M} 0}=\int_{-H(y)}^{0}<v><c>d z$,

$F_{\mathrm{M} 2}=\int_{-H(y)}^{0}<v_{\mathrm{M} 2} c_{\mathrm{M} 2}>d z$ etc,

and $F_{\text {diff }}$ denotes the diffusive part of the net lateral transport. By using the harmonic decomposition Eq. 8, it is possible to identify the dominant tidal contributions to the lateral sediment balance.

\section{Results}

In this section, numerical model results regarding lateral flow and sediment dynamics will be presented for both no slip and partial slip velocity near the bed. These results will be presented for two different cases. The first case is that of a deep, well-mixed and tidally dominated tidal channel (hereafter referred to as "deep channel"). The second case is a more shallow, partially mixed estuary that resembles James River.

Regarding the flow, the focus is on the cross-channel velocity component, as it determines the lateral sediment transport and thereby controls the location of turbidity maxima in estuarine cross-sections. Also, the density and sediment distribution will be presented. In particular, the residual and semi-diurnal components 
Table 1 Full listing of model parameters that have been used for the numerical simulations

\begin{tabular}{|c|c|c|}
\hline Symbol & Meaning & Value \\
\hline $\bar{U}$ & Cross-sectionally averaged $M_{2}$ velocity & $0.8 \mathrm{~m} \mathrm{~s}^{-1}$ \\
\hline$L$ & Channel length & $1,200 \mathrm{~km}$ \\
\hline$B$ & Channel width & $5 \mathrm{~km}$ \\
\hline$L_{0}$ & Location of central part of the intermediate region & $800 \mathrm{~km}$ \\
\hline$L_{1}$ & Transition between landward and intermediate region & $500 \mathrm{~km}$ \\
\hline$L_{2}$ & Transition between seaward and intermediate region & $1,100 \mathrm{~km}$ \\
\hline$H_{\max }$ & Maximum water depth at Gaussian bed profile & $30 \mathrm{~m}$ \\
\hline$b$ & Topographic length scale of Gaussian bed profile & $1,519.2 \mathrm{~m}$ \\
\hline $\bar{H}$ & Width averaged depth of Gaussian bed profile & $15.8 \mathrm{~m}$ \\
\hline$H_{1}$ & Maximum bottom depth in landward part of channel & $12 \mathrm{~m}$ \\
\hline $\mathrm{H}_{2}$ & Minimum bottom depth in landward part of channel & $3 \mathrm{~m}$ \\
\hline$S_{\text {sea }}$ & Salinity at seaward boundary & $33.5 \mathrm{psu}$ \\
\hline$S_{\text {land }}$ & Salinity at landward boundary & $0.5 \mathrm{psu}$ \\
\hline$f$ & Coriolis parameter & $10^{-4} \mathrm{~s}^{-1}$ \\
\hline$A_{\mathrm{v}}$ & Vertical viscosity coefficient & $0.02 \mathrm{~m}^{2} \mathrm{~s}^{-1}$ \\
\hline$K_{\mathrm{v}}$ & Vertical diffusion coefficient for sediment and salinity & $0.02 \mathrm{~m}^{2} \mathrm{~s}^{-1}$ \\
\hline$K_{\mathrm{h}}$ & Horizontal diffusion coefficient & $10 \mathrm{~m}^{2} \mathrm{~s}^{-1}$ \\
\hline$d_{\mathrm{s}}$ & Sediment grain size & $20 \mu \mathrm{m}$ \\
\hline$w_{\mathrm{s}}$ & Sediment settling velocity & $0.3 \mathrm{~mm} \mathrm{~s}^{-1}$ \\
\hline$g$ & Gravitational acceleration & $9.81 \mathrm{~m} \mathrm{~s}^{-2}$ \\
\hline
\end{tabular}

of these variables are presented as they are the key quantities that control the lateral sediment transport.

\subsection{Deep channel case}

The adopted parameter values for the deep-channel model are listed in Table 1. The boundary values for salinity and the extension $L_{2}-L_{1}$ of the intermediate zone are chosen such that the along-channel gradient of residual density is approximately equal to $10^{-4} \mathrm{~kg} \mathrm{~m}^{-4}$.

The slip parameter value for the no-slip boundary condition is $s=0.122 \mathrm{~m} \mathrm{~s}^{-1}$, while the partial slip con- dition corresponds to $s=4.98 \times 10^{-4} \mathrm{~m} \mathrm{~s}^{-1}$. In terms of the dimensionless parameter $s \bar{H} / A_{\mathrm{v}}$ these values correspond to $s \bar{H} / A_{\mathrm{v}}=96.4 \gg 1$ and $s \bar{H} / A_{\mathrm{v}}=0.39$, respectively.

\subsubsection{Cross-channel velocity}

Figure 2 shows the residual lateral velocity for both no slip and partial slip. We see that the no-slip condition gives a single, clockwise rotation. The maximum flow velocity is $\sim 6 \mathrm{~cm} \mathrm{~s}^{-1}$. The partial slip case is characterised by two counter-rotating cells, rather than just a

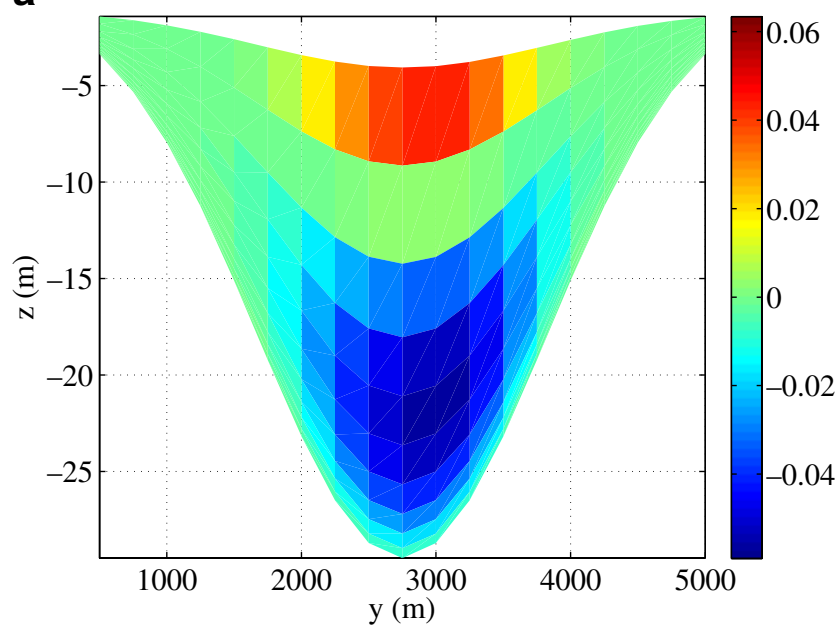

b

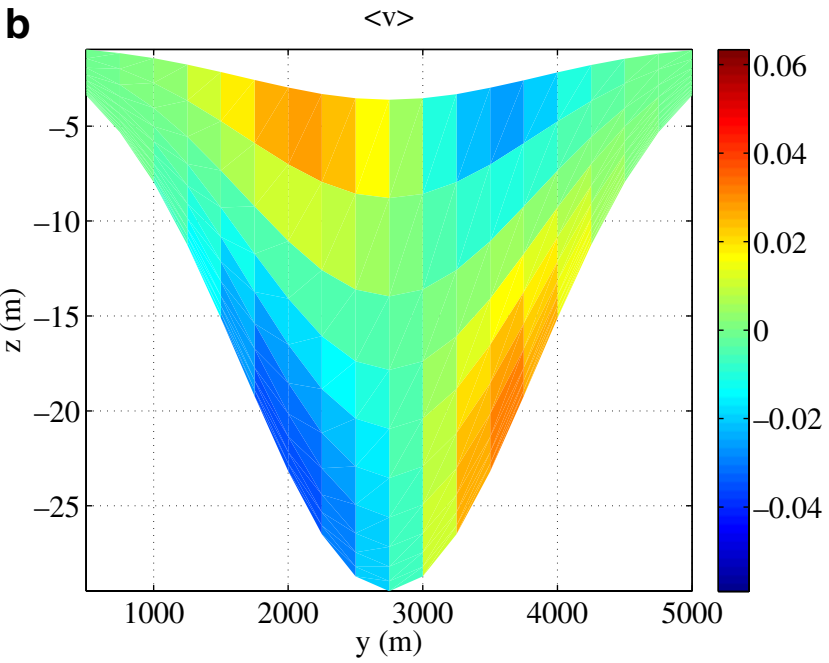

Fig. 2 Residual component of lateral flow $<v>\left(\mathrm{m} \mathrm{s}^{-1}\right)$ for the deep-channel model: a no slip, b partial slip. The colour scaling for both panels is identical 

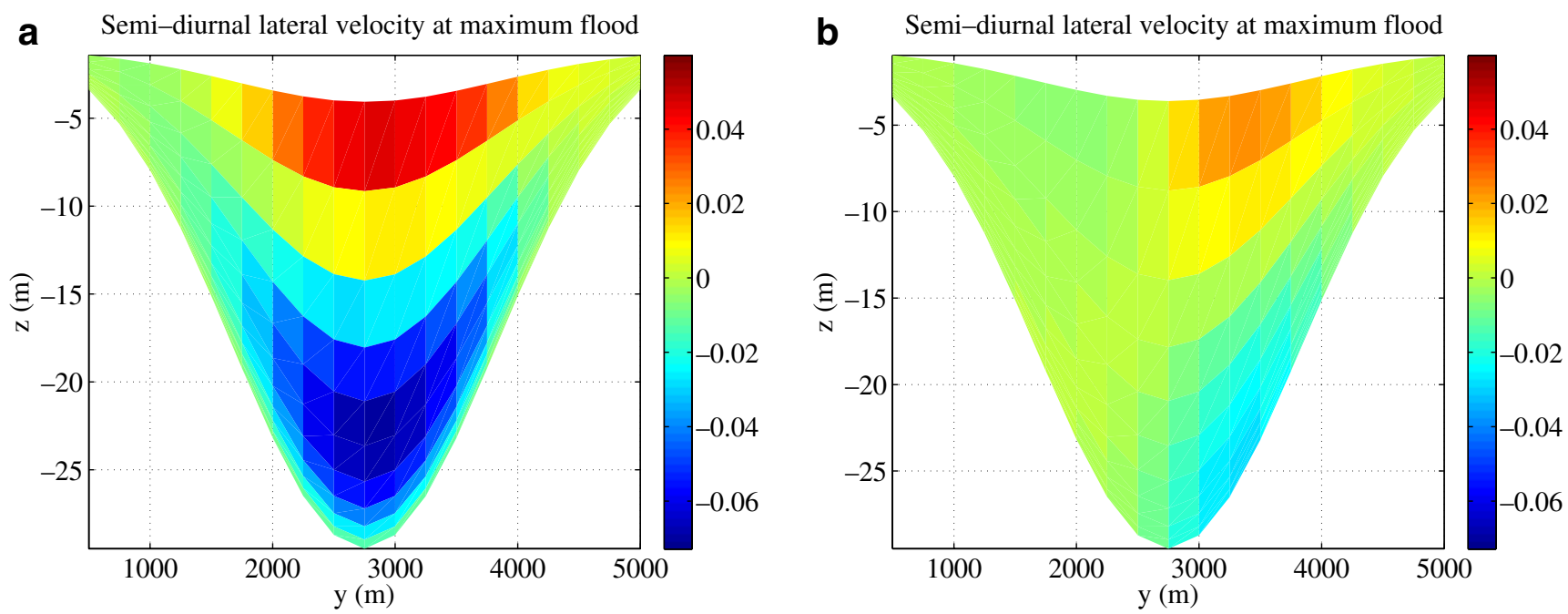

Fig. 3 Semi-diurnal component of lateral flow $v_{\mathrm{M} 2}$ around maximum flood $\left(\mathrm{m} \mathrm{s}^{-1}\right)$ for the deep-channel model: a no slip, b partial slip. The colour scaling for both panels is equal

one. At the centreline of the channel, the resulting flow is diverging (converging) near the bed (near the surface). The maximum flow velocities $\left(\sim 3 \mathrm{~cm} \mathrm{~s}^{-1}\right)$ are almost twice as low as compared to the no-slip case.

The semi-diurnal component $v_{\mathrm{M} 2}$ of the lateral flow at the moment of maximum horizontal flood is shown in Fig. 3. This is essentially the component of $v_{\mathrm{M} 2}$ that is in phase with the semi-diurnal part $c_{\mathrm{M} 2}$ of the sediment distribution (not shown) and, thus, determines the semi-diurnal contribution $<v_{\mathrm{M} 2} c_{\mathrm{M} 2}>$ to the net advective sediment flux. For the no-slip bottom boundary condition (Fig. 3a), this flow is characterised by a single, clockwise circulating cell with maximum cross-channel velocities up to $\sim 6 \mathrm{~cm} \mathrm{~s}^{-1}$. For the partial slip case, the semi-diurnal flow is characterised by a very asymmetric double cell pattern, which is dominated by a strong cell at the right bank. Here, the maximum flow velocities $\left(\sim 3 \mathrm{~cm} \mathrm{~s}^{-1}\right)$ are nearly two times smaller than for the no-slip case.

\subsubsection{Density and sediment distribution}

Figure 4 shows the cross-channel residual density distribution $\langle\rho\rangle$ for both the no-slip and the partial-slip case. For the former case, the residual density has relatively heavy (light) water on the right (left) bank.
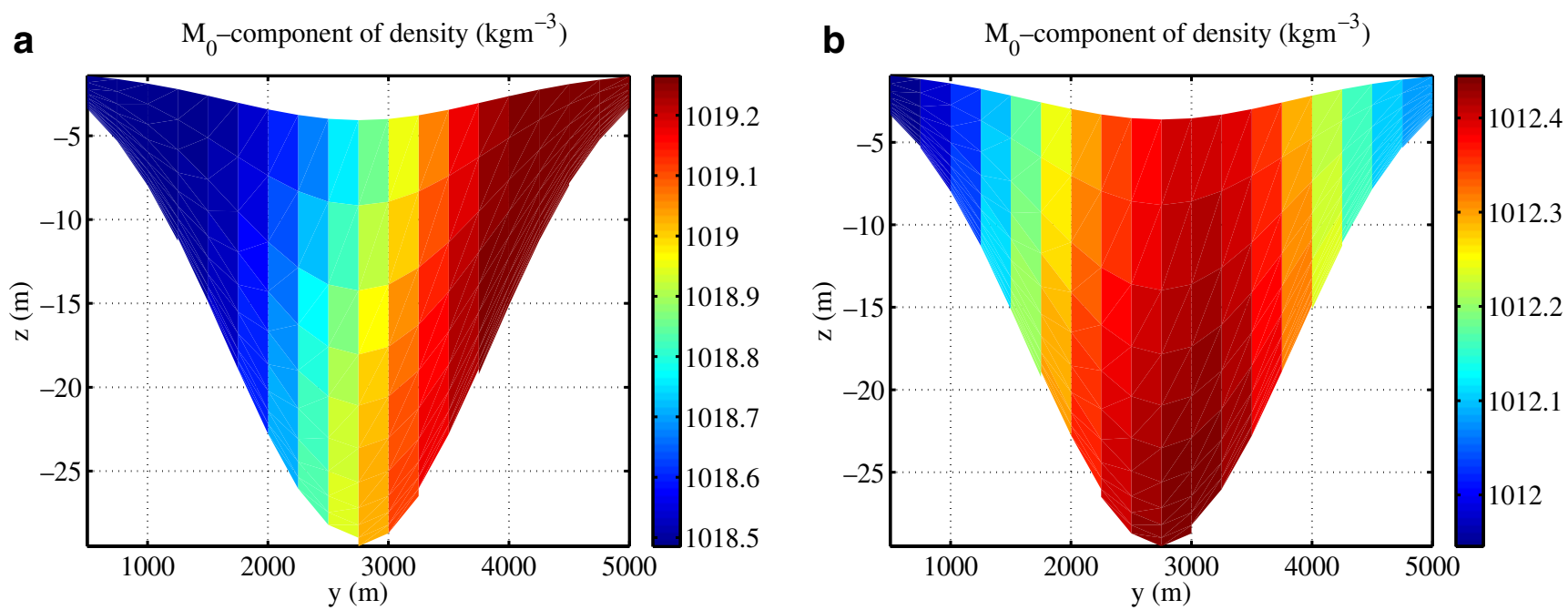

Fig. 4 Cross-channel distribution of residual density $<\rho>\left(\mathrm{kg} \mathrm{m}^{-3}\right)$ for the deep-channel case: a no slip, b partial slip 

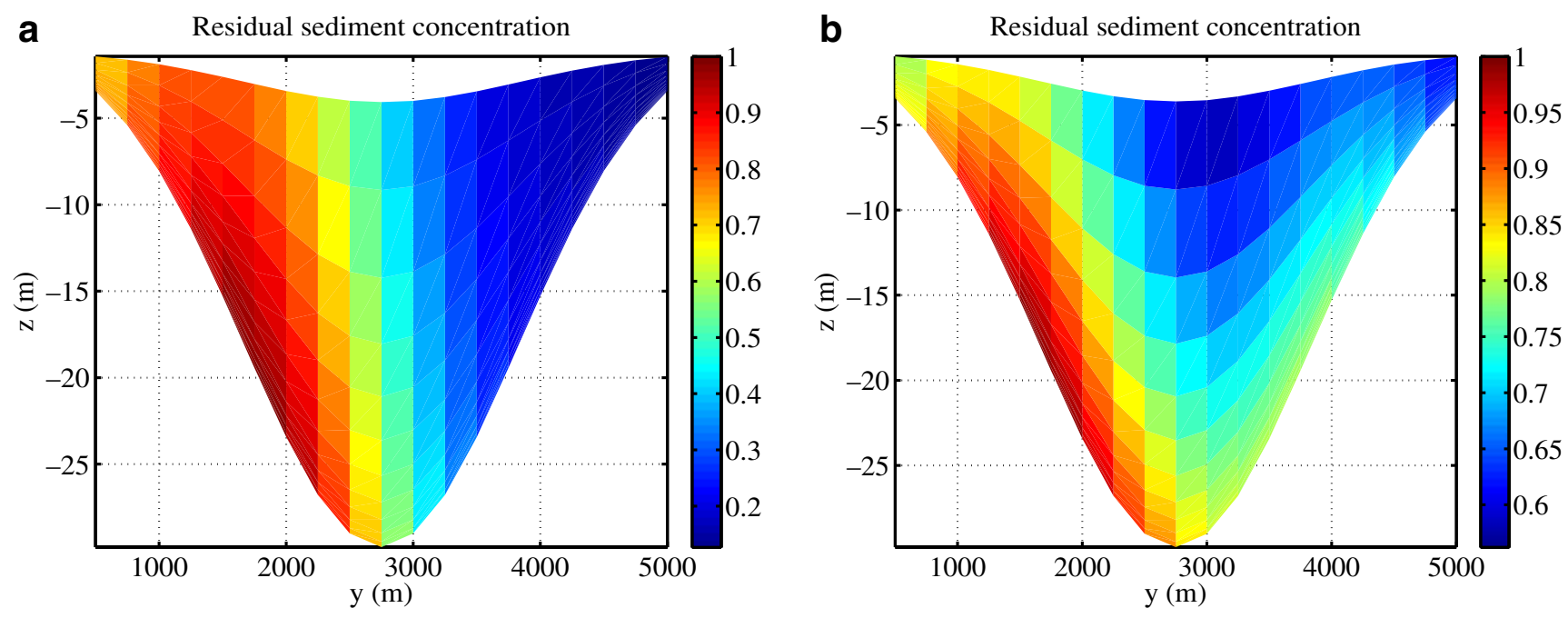

Fig. 5 Cross-channel distribution of relative residual sediment concentration for the deep-channel model: a no slip, b partial slip

The residual density distribution for the partial slip case (Fig. 4b) has relatively heavy (light) water in deeper (shallower) parts. Maximum residual density thus occurs near the centreline of the channel.

Figure 5 shows the results regarding the lateral sediment distribution for the no-slip and partial-slip cases as obtained by the morphodynamic condition Eq. 7 . Figure 5a displays the relative cross-channel residual sediment concentration for the no-slip case. It is found that a maximum in SSC occurs on the left bank. The dominant terms in the lateral transport balance are governed by the residual contribution to the net advective (i.e. $\langle v>\langle c\rangle$ ) and tidally mean diffusive transport.

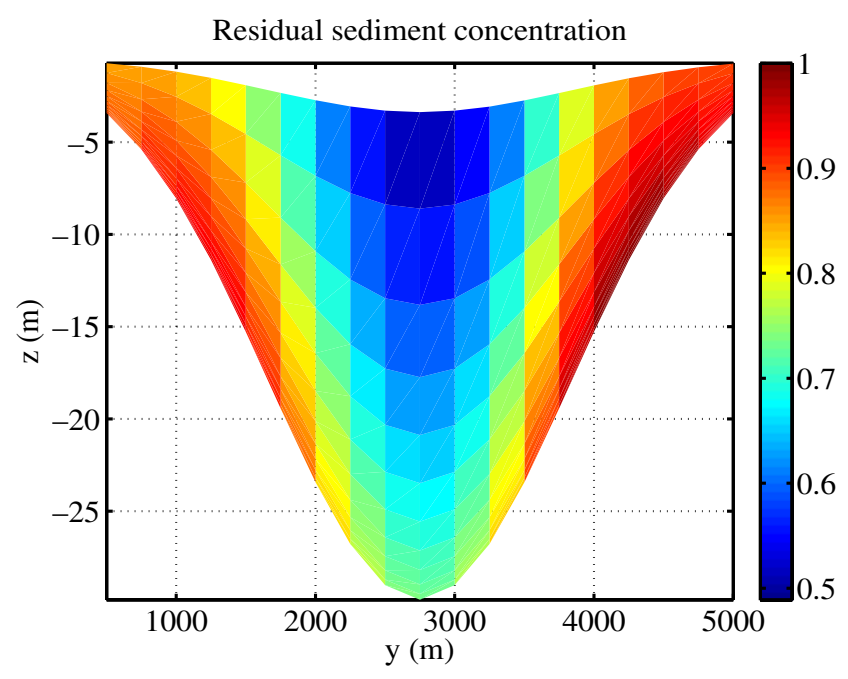

Fig. 6 Relative residual sediment concentration for the deepchannel model in case $s=2.41 \times 10^{-4} \mathrm{~m} \mathrm{~s}^{-1}$
For partial slip (Fig. 5b), there is still a region on the left bank where a maximum in SSC distribution occurs. However, now a turbidity maximum is also observed on the right bank where maximum sediment concentrations are approximately $20 \%$ lower. This second turbidity maximum becomes more pronounced as the slip parameter values are lowered further, see Fig. 6, which shows the density distribution for $s=2.41 \times 10^{-4} \mathrm{~m} \mathrm{~s}^{-1}$. For these partial slip cases, cross-channel sediment transport balance is still mediated primarily by residual velocity and residual sediment concentration.

\subsection{James River case}

In this subsection, we will present results regarding a tidal channel that resembles the conditions in the James River estuary. The adopted model parameters are shown in Table 2 . The seaward and landward salinity values and the extension $L_{2}-L_{1}$ of the intermediate

Table 2 Values for the model parameters that have been used for the James River estuary case

\begin{tabular}{ll}
\hline Symbol & Value \\
\hline$U$ & $0.4 \mathrm{~m} \mathrm{~s}^{-1}$ \\
$L_{1}$ & $650 \mathrm{~km}$ \\
$L_{2}$ & $950 \mathrm{~km}$ \\
$H_{\max }$ & $12 \mathrm{~m}$ \\
$b$ & $1,585.9 \mathrm{~m}$ \\
$\bar{H}$ & $6.57 \mathrm{~m}$ \\
$A_{\mathrm{v}}$ & $0.001 \mathrm{~m}^{2} \mathrm{~s}^{-1}$ \\
$K_{\mathrm{v}}$ & $0.001 \mathrm{~m}^{2} \mathrm{~s}^{-1}$ \\
\hline
\end{tabular}

Parameter values not listed here have been taken equal to the values listed in Table 1 

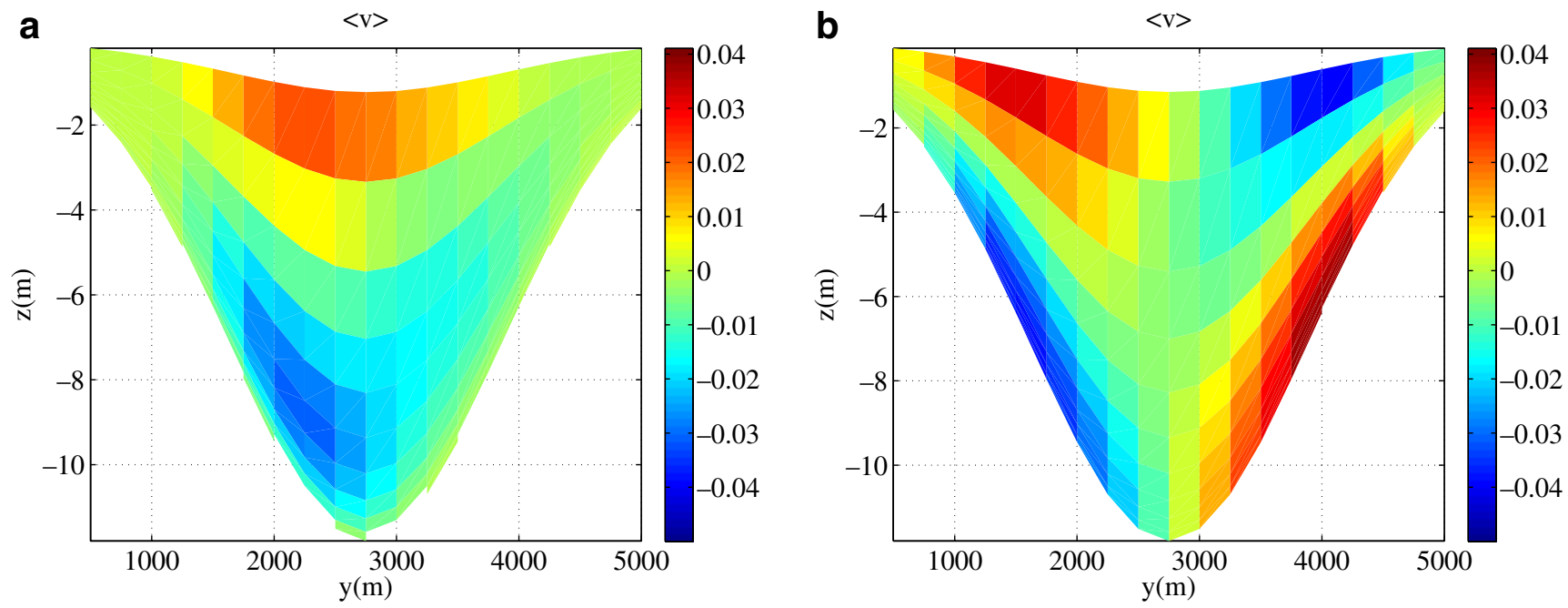

Fig. 7 Residual cross-channel velocity $<v>$ in the James River model for both no-slip and partial-slip cases. The colour scaling is the same for both panels. a No slip. b Partial slip

region have been chosen such that the along-channel gradient of residual density is $\sim 3-4 \times 10^{-4} \mathrm{~kg} \mathrm{~m}^{-4}$.

The tidal flow (typical velocity amplitude $U \sim$ $0.4 \mathrm{~m} \mathrm{~s}^{-1}$ ) still prevails over the baroclinic alongchannel residual flow (values up to $20 \mathrm{~cm} \mathrm{~s}^{-1}$ ), albeit the ratio of the two velocity amplitudes is not as large as that in the deep channel.

\subsubsection{Cross-channel velocity}

The residual lateral velocity for both the no-slip and the partial-slip case is shown in Fig. 7. Just like the deep channel case (Fig. 2), we see that the no-slip bottom boundary condition gives rise to a single clockwise rotating circulation cell, while a partial slip condition yields a double-cell circulation. However, contrary to the deep-channel case, the maximum residual flow velocities are larger for the partial slip case $\left(\sim 5 \mathrm{~cm} \mathrm{~s}^{-1}\right.$ vs $\sim 3 \mathrm{~cm} \mathrm{~s}^{-1}$ ).

Figure 8 shows the semi-diurnal component of the cross-channel flow at maximum horizontal flood for both no slip and partial slip. The flow patterns are similar and are characterised by a strongly asymmetric double cell. Also, typical maximum flow velocities for both cases are approximately equal $\left(\sim 4 \mathrm{~cm} \mathrm{~s}^{-1}\right)$. a Semi-diurnal lateral velocity at max. horizontal flood

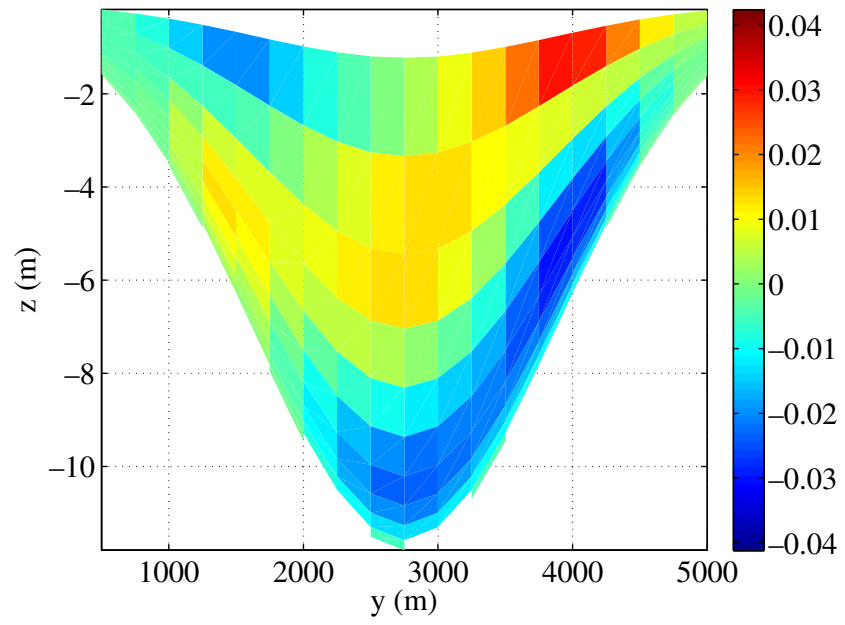

b Semi-diurnal lateral velocity at max. horizontal flood

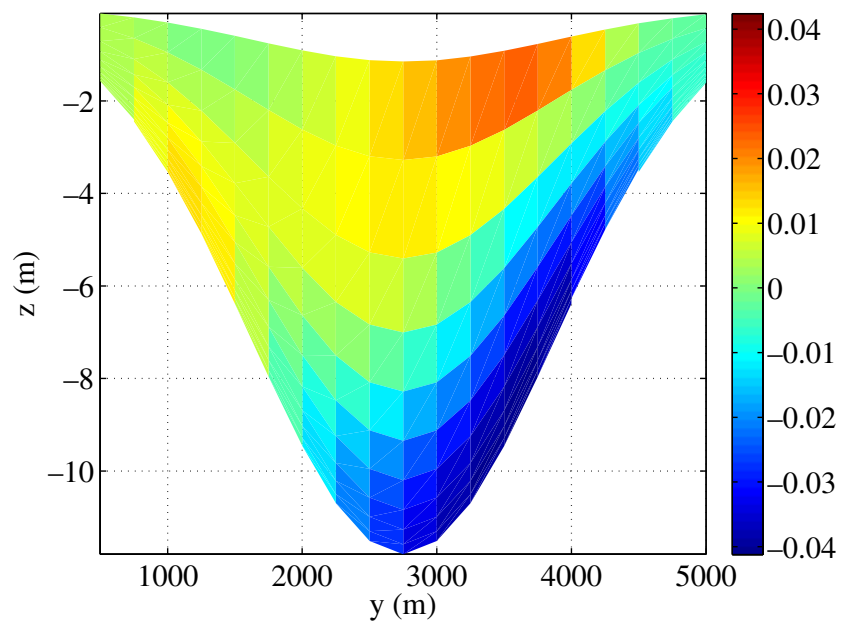

Fig. 8 Semi-diurnal cross-channel velocity $v_{\mathrm{M} 2}$ at maximum horizontal flood for the James River model: a no slip, b partial slip. Both panels have the same colour scaling 

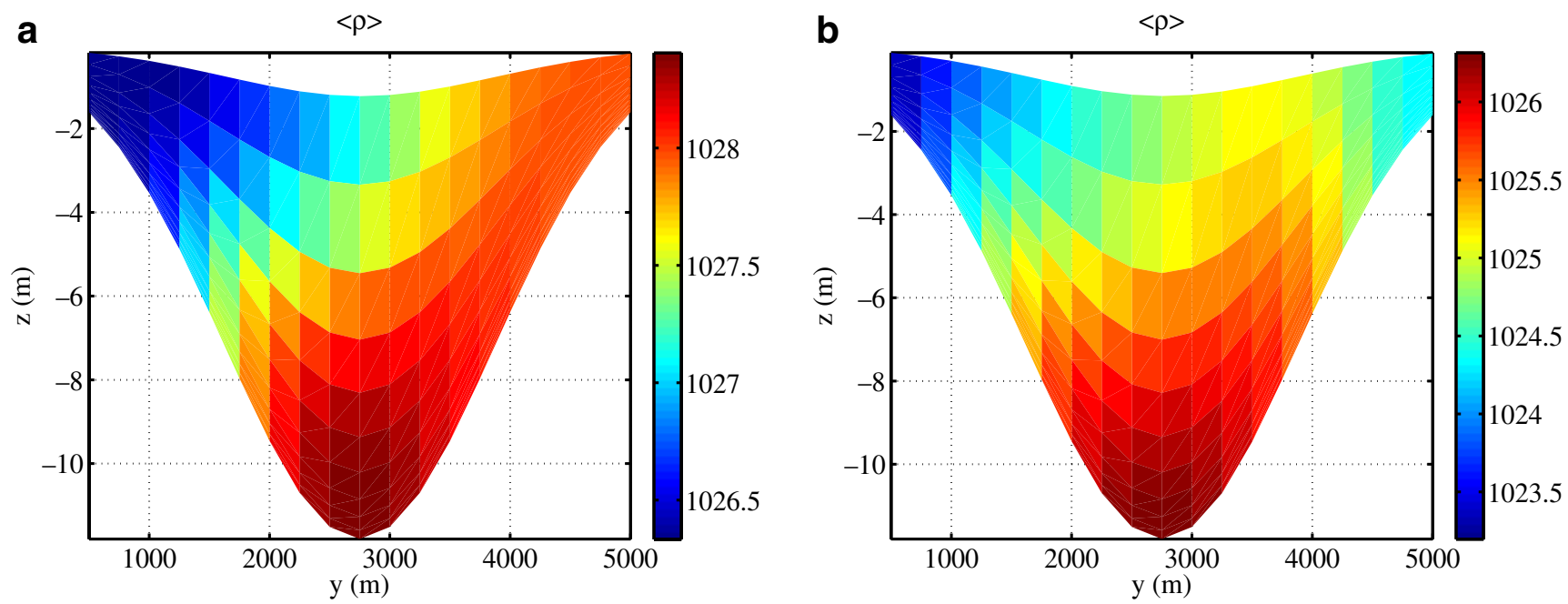

Fig. 9 Transversal distribution of the residual density $\langle\rho\rangle$ in the James River model for both no slip and partial slip case. a No slip. b Partial slip

\subsubsection{Density and sediment distribution}

The cross-sectional distribution of residual density is shown in Fig. 9. Similar to the deep channel model, the no-slip case shows a tendency for a residual density distribution that has relatively heavy water near the right bank. In contrast, the partial slip case exhibits a more symmetric distribution with relatively heavy (light) water collecting into deep (shallow) parts of the channel. Hence, as velocity slip near the bed is increased, the location of the residual density maximum shifts from the right bank to the deeper part of the channel. Figures 10 and 11 show the relative averaged sediment concentration $\langle c>$ and the sediment balance terms for no slip and partial slip, respectively. The spatial pattern of $c_{\mathrm{M} 2}$ at maximum horizontal flood (not shown here) reveals that its near-bed values are positive in the deep parts of the channel.

Contrary to the deep tidal channel case, we see that a single maximum of SSC now occurs at the left bank for both the no-slip and the partial-slip case. Also, we now find that the residual concentration $\langle c\rangle$ and velocity $\langle v\rangle$ are not the only contributors to the advective sediment transport. The semi-diurnal part of the net advective sediment transport (i.e. $F_{\mathrm{M} 2}$ ) constitutes up to $25 \%$ of the total advective sediment transport. a

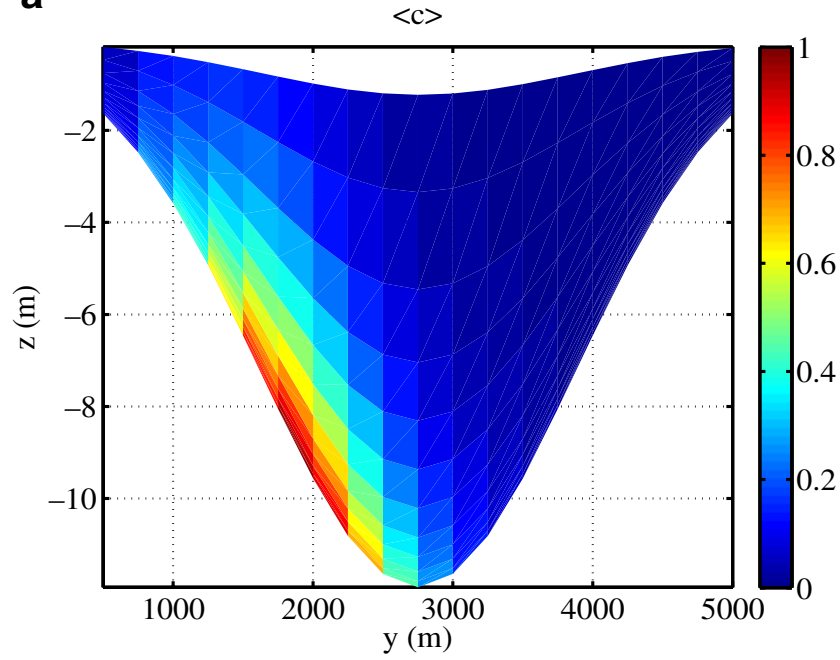

b

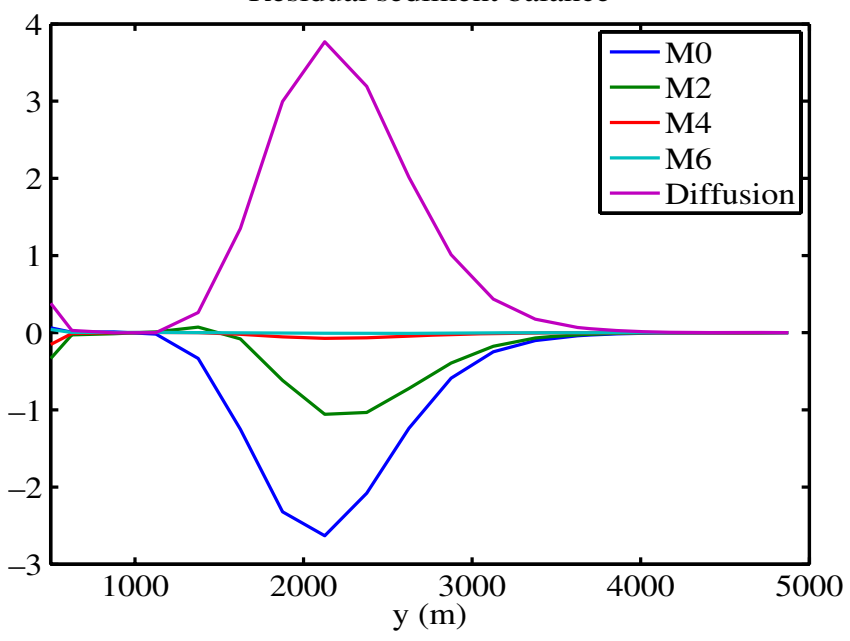

Fig. 10 Lateral sediment balance for James River (no slip): a cross-channel distribution of relative residual sediment concentration, and $\mathbf{b}$ contribution of individual harmonic components to the lateral sediment balance (see Eq. 8) 

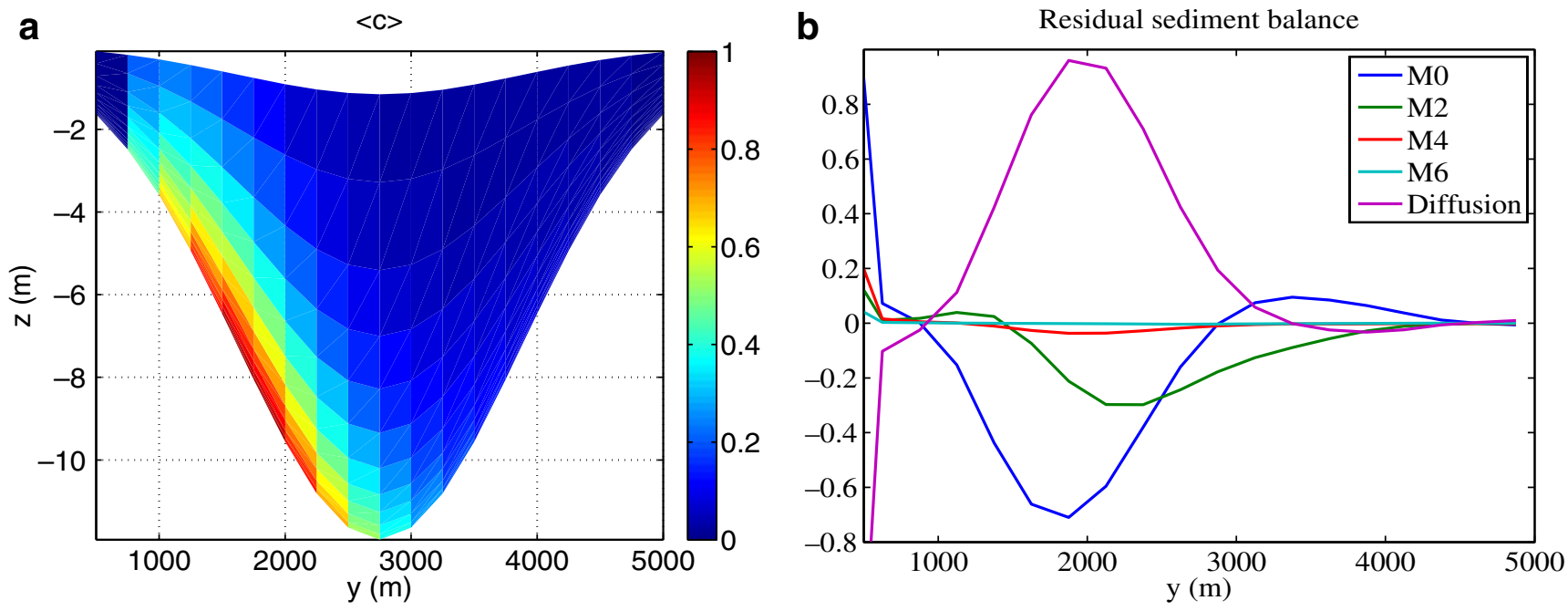

Fig. 11 Lateral sediment balance for James River (partial slip): a cross-channel distribution of relative residual sediment concentration, and $\mathbf{b}$ contribution of individual harmonic components to the lateral sediment balance (see Eq. 8)

\subsubsection{Sensitivity to model parameters}

We have investigated the robustness of the single peaked SSC distribution for the James River case by studying the sediment balance as a function of settling velocity and vertical viscosity and diffusion.

It appears that the qualitative sediment distribution is not very sensitive to the value of the sediment settling velocity. Specifically, when varying $w_{\mathrm{s}}$ between $0.1 \mathrm{~mm} \mathrm{~s}^{-1}$ and $0.9 \mathrm{~mm} \mathrm{~s}^{-1}$, we found a persistent negative contribution of $F_{\mathrm{M} 2}$, which increased from $20 \%$ to almost $50 \%$ of the total advective sediment transport.

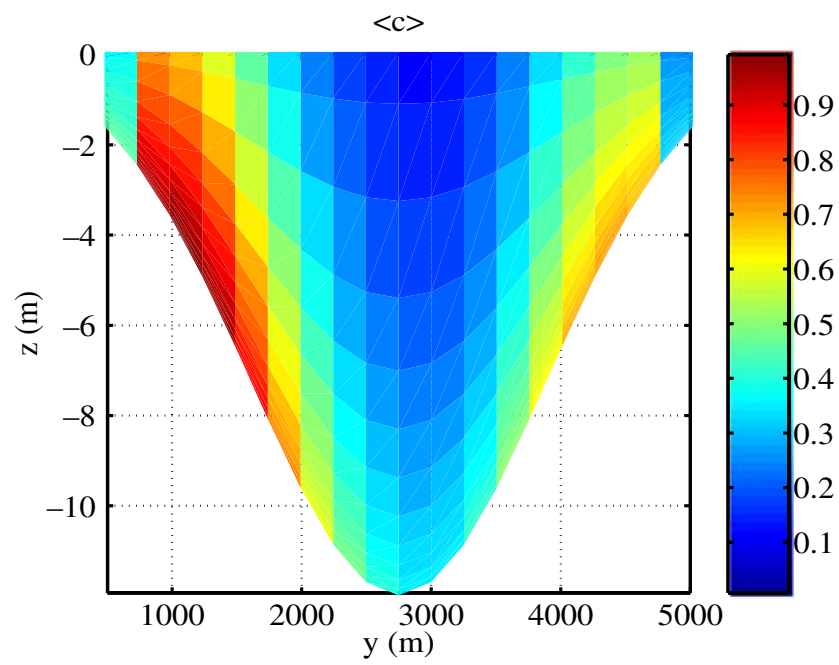

Fig. 12 Relative residual sediment concentration in the James River model for a partial slip boundary condition with increased vertical mixing $\left(A_{\mathrm{v}}=K_{\mathrm{v}}=0.0032 \mathrm{~m}^{2} \mathrm{~s}^{-1}\right)$
This negative (i.e. leftward directed) sediment transport gives a preferred SSC maximum at the left bank.

The sediment distribution is sensitive to the value of the vertical viscosity $A_{\mathrm{v}}$. Explicitly, for a higher value of viscosity $\left(A_{\mathrm{v}}=0.0032 \mathrm{~m}^{2} \mathrm{~s}^{-1}\right)$, a double peaked SSC distribution occurs for partial slip (see Fig. 12). For the no-slip case, a single SSC maximum at the left bank is obtained. This is very similar to the findings regarding the deep, well-mixed estuary. In fact, the sediment balance is again dominated by residual sediment concentration and residual lateral velocity. The results are qualitatively the same as for the deep, well-mixed tidal channel (see Fig. 5).

\section{Discussion}

4.1 Deep channel case: effect of partial slip on model results

\subsubsection{Cross-channel flow}

First, we briefly discuss the effect of partial slip on Coriolis induced secondary (i.e. cross-channel) circulation. This is relevant for explaining the semi-diurnal lateral flow, as well as the residual density distribution. The secondary circulation is an intrinsic threedimensional effect which arises because of a local imbalance between barotropic forcing (water level gradient) and the Coriolis force. The former is constant over the water depth, while the Coriolis force increases towards the surface as a result of the vertical shear of velocity. While both forces are in balance in a depth- 
averaged sense, there is a local imbalance along the vertical, and this imbalance drives secondary flows that are perpendicular to the direction of the main flow.

Note that the degree of imbalance (i.e. the strength of secondary flows) depends on the vertical velocity shear. Indeed, due to vertical shear of velocity, the Coriolis force varies with depth and cannot be balanced by a depth-independent barotropic pressure gradient. Hence, for fixed vertical eddy viscosity and vertically averaged velocity, a smaller velocity difference between surface and bottom will generate weaker secondary circulation. In particular, this implies that Coriolis induced circulation will be weaker when nearbed velocity slip is introduced. Since the no-slip and partial-slip model results refer to the same value of $A_{\mathrm{V}}$ and $U$, we expect Coriolis effects to be relatively less important for the latter case.

The transversal variation of residual flow (as indicated by the lateral component $\langle v\rangle$ ) appears to be a direct consequence of the cross-channel distribution of residual density. Indeed, the single clockwise rotating cell in Fig. 2a is consistent with a residual density distribution with a maximum on the right bank (Fig. 4a). Similarly, the more symmetric density distribution in the partial slip case (Fig. 4b) generates a double cell circulation pattern which is diverging near the bed (see Fig. 2b).

If we compare the $M_{2}$ lateral flow for the no-slip and partial-slip cases (Fig. 3a and b, respectively), we see two main differences. First, the maximum flow speed is lower for partial slip. Second, the cross-channel flow is a single circulation pattern for no slip while it is an asymmetric double cell for partial slip. These results are a consequence of the fact that the semidiurnal cross-channel flow consists of two different contributions. The first contribution is a single cell which originates from Coriolis deflection. This is essentially the clockwise rotating cell as displayed in Fig. 3a. The second contribution is a double-cell pattern which is due to the semi-diurnal variation of the density field. To show this baroclinic contribution more explicitly, Fig. 13 shows the cross-channel structure of the semidiurnal component of density $\rho_{\mathrm{M} 2}$ during maximum horizontal flood. At this moment, the cross-channel average of $\rho_{\mathrm{M} 2}$ is nearly zero. We see that water in the deep (shallow) parts is relatively light (heavy), i.e. density in the central part lags behind relative to the banks. This density distribution sets up a double cell flow pattern that has a near-bed flow towards the deep channel and a near-surface flow that is diverging away from it. This baroclinic circulation enhances the Coriolis induced flow at the right bank, but counteracts it on the left bank. This gives a strongly asymmetric

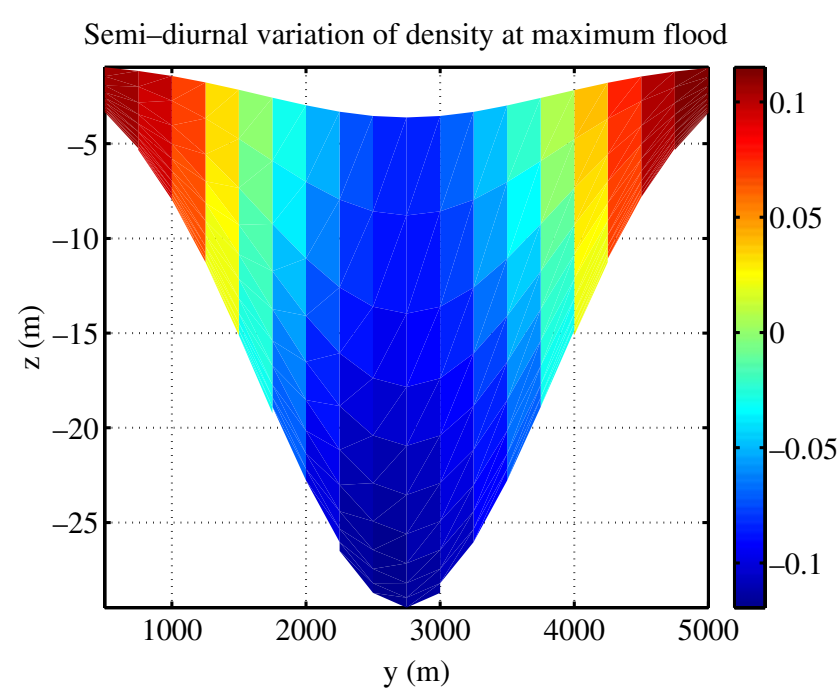

Fig. 13 Structure of the semi-diurnal component of density $\left(\mathrm{kg} \mathrm{m}^{-3}\right)$ at maximum horizontal flood for $s=4.98 \times 10^{-4} \mathrm{~m} \mathrm{~s}^{-1}$

double-cell pattern, which is dominated by the cell on the right bank.

\subsubsection{Residual cross-channel density distribution}

The residual density distribution for the no-slip case (Fig. 4a) is a combination of two effects. First, the salinity field is advected by the along-channel, semi-diurnal flow. Second, the along-channel flow also generates a semi-diurnal lateral circulation by Coriolis deflection. The advection of the time-dependent density field with the semi-diurnal lateral velocity gives a net salt flux to the right bank of the channel. This will now be explained.

During flood (see Fig. 14a), Coriolis deflection will generate a clockwise rotating cell which has lateral velocity to the right (left) near the surface (near the bottom). Furthermore, the along-channel velocity magnitude increases towards the surface. Hence, fluid particles in the upper parts of the water column originate

a

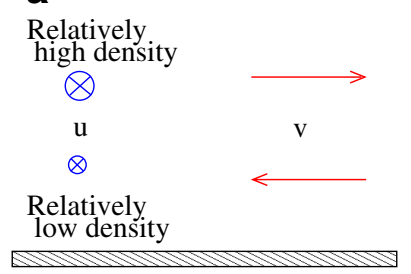

b

Fig. 14 Behaviour of along-channel flow (blue), lateral velocity (red) and density in a cross-section of the channel during flood (a) and ebb (b). Large (small) blue circles indicate relatively high (low) along-channel velocity

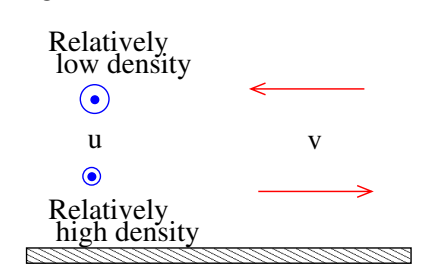

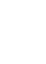


from a region that is more down-estuary than fluid particles in the lower parts. Near the surface, the lateral advective sediment flux $v s$ will transport relatively dense water to the right. Similarly, relatively light water is transported to the left in the lower parts of the water column. The vertically integrated effect of these two contributions is a net advective transport of salinity to the right.

During ebb (Fig. 14b), the flow is reversed and a counter-clockwise rotation cell will be formed. Fluid particles in the upper part of the water column now originate from more up-estuary-located regions and, hence, will be less dense than water near the bottom. So now that the density decreases towards the surface, relatively light water is transported to the left, whereas relatively dense water is transported to the right. The vertically integrated effect of these to fluxes is again a net transport of salinity to the right.

The tidally averaged lateral salt transport to the right bank of the channel sets up a salinity gradient that is opposite to the advective flux. This density gradient provides a net diffusive transport to the left bank.

Note that the density stratification during flood is unstable (relatively heavy water on top of relatively light water). In the present model, this does not give rise to enhanced mixing since the turbulence formulation (constant coefficient for vertical diffusion) does not include buoyancy effects. If such effects are to be included, it is expected that there will be almost no net lateral salinity transport during flood.

In case of partial slip, the lateral circulation by Coriolis deflection is much weaker (see Section 4.1.1). The cross-channel distribution of residual density is then governed by gravitational circulation, which transports relatively salt (fresh) water in deeper (shallower) parts of the channel. Hence, deep parts are more saline than shallow parts, which explains the density distribution as shown in Fig. 4b.

\subsubsection{Residual sediment distribution}

It is found that the cross-channel distribution of sediment is mainly governed by residual flow and sediment. Hence, the residual advective sediment flux is mainly given by $\langle v\rangle\langle c\rangle$. Since the sediment concentration decreases towards the surface, this indicates that the vertically integrated advective flux is determined by the lateral velocity in the lower part of the water column.

For the no-slip case (Fig. 2a) this gives a net sediment transport to the left bank, which explains the presence of a sediment maximum of the left side of the channel. Along with this sediment accumulation, a diffusive transport is set up that balances the advective sediment transport. For lower values of the slip parameter, Coriolis effects become of minor importance in the dynamics, so that the density distribution becomes more symmetric with respect to the channel's central axis. As a result, an anti-symmetric cross-channel residual flow occurs, which is diverging near the bed. The sediment fluxes induced by this flow give rise to two turbidity maxima, which are located on either side of the channel.

\subsection{James river}

\subsubsection{Cross-channel flow and density distribution}

The residual lateral flow $\langle v\rangle$ behaves qualitatively similar to the deep channel flow case (see Fig. 7). Indeed, for the James River, one also finds a transition from a single to a double circulation cell pattern as the amount of near-bed velocity slip is increased. Similarly, these flow patterns seem to reflect the crosschannel distribution of residual density as shown in Fig. 9. Indeed, the no-slip case (Fig. 9a) gives a (depthaveraged) density maximum towards the right bank, which sets up a clockwise rotating cell. In the case of partial slip (Fig. 9b), the most saline water occurs in the deep channel, thereby setting up a double-cell pattern, as shown in Fig. $7 b$.

The qualitative similarity with residual flow patterns for the deep-channel case indicates that the Coriolis force plays a significant role in the lateral distribution of residual density (see Sections 4.1.1 and 4.1.2). For both no slip and partial slip, the semi-diurnal part of the lateral velocity component (Fig. 8) shows a clear doublecell pattern at maximum horizontal flood. Moreover, the maximum flow speed $\sim 4 \mathrm{~cm} \mathrm{~s}^{-1}$ is approximately equal for both cases. In view of the discussion of the origin of the semi-diurnal variation of density (Section 4.1.1), this indicates that the semi-diurnal cross-channel flow that arises from Coriolis deflection is relatively small. In other words: the semi-diurnal lateral flow is dominated by baroclinic forcing.

\subsubsection{Sediment distribution}

As remarked in Section 3.2.2, the semi-diurnal part $c_{\mathrm{M} 2}$ of the sediment concentration has positive near-bed values during maximum flood. This is because the residual inflow due to gravitational circulation acts in the same direction as the tidal along-channel flow, which gives an increase of erosion. During ebb, residual and tidal flows counteract, which leads to a decrease of erosion and, thus, to negative near-bed values of $c_{\mathrm{M} 2}$. 
Contrary to the deep tidal channel case, we see that a single maximum of SSC occurs at the left bank for both no slip and partial slip formulation (see Figs. 10 and 11). Moreover, we find that the advective sediment transport is not determined by residual concentration $<c>$ and velocity $\langle v>$ alone. The semi-diurnal part of the net advective sediment transport (i.e. $F_{\mathrm{M} 2}$, see Eq. 8) contributes up to $25 \%$ of the total advective sediment transport. In fact, this latter contribution is negative for both no slip and partial slip and, thus, acts to transport sediment to the left bank of the channel.

The negative sediment transport contribution from $F_{\mathrm{M} 2}$ can be understood as follows. During maximum flood, $v_{\mathrm{M} 2}$ is negative in the deeper parts (see Fig. 8), while near-bed values of $c_{\mathrm{M} 2}$ are positive (see above). These signs are reversed during maximum ebb. Hence, the near-bed sediment flux $<v_{\mathrm{M} 2} c_{\mathrm{M} 2}>$ that stems from semi-diurnal flow and sediment is negative throughout the tidal cycle, which gives a negative sediment transport $F_{\mathrm{M} 2}$.

In the no-slip case, the semi-diurnal sediment transport $F_{\mathrm{M} 2}$ behaves very similar to the contribution $F_{\mathrm{M} 0}$ that stems from residuals. Just as for the deep wellmixed tidal channel, $F_{\mathrm{M} 0}$ changes sign as velocity slip is introduced near the bed. As a result, $F_{\mathrm{M} 0}$ and $F_{\mathrm{M} 2}$ act together at the left side of the channel while they counteract on the right side. For the specific choice of parameters adopted here, $F_{\mathrm{M} 0}$ and $F_{\mathrm{M} 2}$ roughly cancel on the right side. As a result, there is a total advective transport that points to the left, which gives rise to a single SSC maximum at the left bank.

\section{Summary and conclusions}

In this paper, a numerical model approach has been adopted to study the effect of partial slip formulation on the cross-channel variation of flow and sediment. The latter is described by assuming a local vertical sediment balance (Eq. 4) in conjunction with a morphodynamic equilibrium condition for the lateral sediment transport (Eq. 7). This treatment of sediment transport is only justified if advective processes are small compared to sediment settling and upward diffusion. As a consequence, spatial settling effects are not included in the sediment transport module. Such processes have been shown to be important for along-channel distribution of sediment (Postma 1961). Whilst the use of the current sediment module gives results that agree qualitatively with field data for a no-slip boundary condition (Huijts et al. 2006), this is not yet established for the partial-slip case. Besides, for situations where advective contributions are not negligible, a full 2DV sediment equation should be solved in order to analyse the effect of spatial settling lag.

For a deep, well-mixed and tidally dominated channel, it is found that the use of a partial slip bottom boundary condition gives a number of qualitative differences as compared to the no-slip case. Most importantly, the use of a partial slip boundary condition gives a decrease of the relative importance of Coriolis force on cross-channel dynamics. This gives, among others, a reduced contribution of Coriolis deflection to the semidiurnal cross-channel flow. Also, as the slip parameter $s$ is lowered, the reduced importance of Coriolis deflection gives rise to a more symmetric distribution of residual flow, salinity and sediment. Hence, the use of partial slip leads to the occurrence of two locations where the mean sediment concentration attains a maximum, whereas a no-slip model gives only a single maximum.

Besides these differences with the no slip case, there are also a number of interesting similarities. First, also for the partial slip case, it is found that the crosschannel residual flow mainly stems from the lateral variation of residual density. Also, the transverse sediment balance (Eq. 8) is still primarily mediated by residual cross-channel flow $\langle v\rangle$ and sediment concentration $<c>$.

For a more shallow, partially mixed estuary that represents typical conditions in the James River estuary, both no slip and partial slip appear to give a SSC maximum at the left bank. This sediment distribution is reflected by a change in the cross-channel sediment balance. Contrary to the case of a deep, well-mixed tidal channel, the semi-diurnal contributions to both sediment and lateral flow play an important role in the cross-channel sediment balance. These contributions constitute a net advective sediment transport that is directed towards the left bank; hence, they introduce preference for a SSC maximum at the left bank. As both vertical viscosity and diff usion are increased, however, a double peaked SSC distribution is recovered, while the cross-channel sediment balance is again predominantly governed by residual flow and residual sediment distribution.

Acknowledgement The authors wish to thank one of the referees (C. T. Friedrichs) for helpful comments on the manuscript.

\section{References}

Blake AC, Kineke GC, Milligan TG, Alexander CR (2001) Sediment trapping and transport in the ACE Basin, South Carolina. Estuaries 24:721-733 
Burchard H, Bolding K, Villarreal MR (2004) Three-dimensional modelling of estuarine turbidity maxima in a tidal estuary. Ocean Dyn 54:250-265

Csanady GT (1982) Circulation in the coastal ocean. Reidel, Dordrecht

Festa JF, Hansen DV (1978) Turbidity maxima in partially mixed estuaries: a two-dimensional numerical model. Estuar Coast Mar Sci 7:347-359

Friedrichs CT, Armbrust BD, de Swart HE (1998) Hydrodynamics and equilibrium sediment dynamics of shallow, funnelshaped tidal estuaries. In: Dronkers J, Scheffers M (eds) Physics of estuaries and coastal seas, PECS 1996. Balkema, Rotterdam, pp 337-343

Fugate DC, Friedrichs CT, Sanford LP (2007) Lateral dynamics and associated transport of sediment in the upper reaches of a partially mixed estuary, Chesapeake Bay, USA. Cont Shelf Res 27:679-698

Garnier J, Servais P, Billen G, Akopian M, Brion N (2001) Lower Seine river and estuary (France) carbon and oxygen budgets during low flow. Estuaries 6B:964-976

Geyer WR, Signell RP, Kineke GC (1998) Lateral trapping of sediment in a partially mixed estuary. In: Dronkers J, Scheffers MBAM (eds) Physics of estuaries and coastal seas, PECS 1996. Balkema, Rotterdam, pp 115-124

Huijts KMH, Schuttelaars HM, de Swart HE, Valle-Levinson A (2006) Lateral trapping of sediment in tidal estuaries: an idealized model study. J Geophys Res 111(C12016). doi:10.1029/2006JC003615

Jay DA, Musiak JD (1994) Particle trapping in estuarine tidal flows. J Geophys Res 99(C10):445-461

Kappenberg J, Grabemann I (2001) Variability of the mixing zones and estuarine turbidity maxima in the Elbe and Weser estuaries. Estuaries 24:699-706

Lin J, Kuo AY (2001) Secondary turbidity maximum in a partially mixed microtidal estuary. Estuaries 24(5):707-720
Maas LRM, van Haren JJM (1987) Observations on the vertical structure of tidal and inertial currents in the central North Sea. J Mar Res 45:293-318

Nichols MM (1972) Sediments of the James River estuary, Virginia. Mem Geol Soc Am 133:169-210

North EW, Chao SY, Sanford LP, Hood RR (2004) The influence of wind and river pulses on an estuarine turbidity maximum: numerical studies and field observations in Chesapeake Bay. Estuaries 27(423-437):132-146. doi:10.1016/j.ecss.2006. 06.032

Postma H (1961) Transport and accumulation of suspended matter in the Dutch Wadden Sea. Neth J Sea Res 1:148 190

Prandle D (2004) Saline intrusion in partially mixed estuaries. Estuar Coast Shelf Sci 59:385-397

Schramkowski GP, Huijts KMH, Schuttelaars HM, de Swart HE (2008) A model comparison of flow and lateral sediment trapping in estuaries. In: Dohmen-Janssen CM, Hulscher SJMH (eds) River, coastal and estuarine morphodynamics: RCEM 2007. IAHR, Taylor \& Francis/Balkema, Leiden, pp 413-420

Stelling GS (1984) On the construction of computational methods for shallow water flow problems. Tech. rep., Rijkswaterstaat

Talke SA, de Swart HE, de Jonge VN (2009) An idealized model and systematic process study of oxygen depletion in highly turbid estuaries. Estuar Coast 32:602-620

Uncles RJ, Joint I, Stephens JA (1998) Transport and retention of suspended particulate matter and bacteria in the HumberOuse Estuary, United Kingdom, and their relationship to hypoxia and anoxia. Estuaries 21:597-612

Uncles RJ, Stephens JA, Law DJ (2006) Turbidity maximum in the macrotidal, highly turbid Humber Estuary, UK: flocs, fluid mud, stationary suspensions and tidal bores. Estuar Coast Shelf Sci 67:30-52 